\title{
Evaluation of Attention Process Training and Brain Injury Education in Persons with Acquired Brain Injury*
}

\author{
McKay Moore Sohlberg ${ }^{1}$, Karen A. McLaughlin ${ }^{1}$, Antonella Pavese ${ }^{1}$, Anke Heidrich ${ }^{1}$, \\ and Michael I. Posner ${ }^{1,2}$ \\ ${ }^{1}$ University of Oregon, Eugene, OR, and ${ }^{2}$ Sackler Institute for Human Brain Function, Cornell Medical \\ College, New York, NY
}

\begin{abstract}
Fourteen patients with stable acquired brain injuries exhibiting attention and working memory deficits were given 10 weeks of attention process training (APT) and 10 weeks of brain injury education in a cross-over design. Structured interviews and neuropsychological tests were used prior to rehabilitation and after both treatments to determine the influence of the interventions on tasks of daily life and performance on attentional networks involving vigilance, orienting, and executive function. The overall results showed that most patients made improvements. Some of these gains were due to practice from repetitive administration of the tests. In addition, the type of intervention also influenced the results. The brain injury education seemed to be most effective in improving self-reports of psychosocial function. APT influenced self-reports of cognitive function and had a stronger influence on performance of executive attention tasks than was found with the brain injury education therapy. Vigilance and orienting networks showed little specific improvement due to therapy. However, vigilance level influenced the improvement with therapy on some tests of executive attention. We consider the implications of these results for future studies of the locus of attentional improvement and for the design of improved interventions.
\end{abstract}

Acquired brain injuries (ABI) frequently produce difficulties in attention and short term memory. Patients with ABI report problems with concentration, distractibility, forgetfulness, and difficulty doing more than one thing at a time (Hinkeldey \& Corrigan, 1990; Mateer, Sohlberg, \& Crinean, 1987). Certain aspects of memory are strongly related to attention (Nissen, 1986; Russell \& D'Hollosy, 1992). Even relatively small decrements in an individual's attention ability may significantly reduce the capacity for new learning and affect academic performance (Kinsella et al., 1997; Kinsella, 1998). Attention impairments frequently accompany executive dysfunction (Mateer \& Mapou, 1996). Patient complaints and research docu- ment problems with the allocation of attentional resources, switching between tasks with different cognitive requirements, time-sharing processing resources and overcoming automatic responses when faced with non-routine situations (Cohen, 1993; Mateer \& Mapou, 1996; Stablum, Leonardi, Mazzoldi, Umilta, \& Morra, 1994).

Most efforts to rehabilitate patients with closed head injury rely on some combination of education and social support, practice, and process training. Education and social support involves supplying individuals with relevant information about their injuries and suggesting strategies to help manage the consequences of the brain damage. It also includes giving opportuni-

\footnotetext{
* The authors extend thanks to Tom Boyd, Ph.D. and Robert Kurlycheck, Ph.D. for their support of this project and their clinical expertise in evaluating the subjects. They also thank the reviewers for their thorough editing and excellent suggestions.

Address Correspondence to: McKay Moore Sohlberg, Communication Disorders and Sciences, 5251 University of Oregon, Eugene, OR 97403, USA. Fax: (541) 346-2586. E-mail: mckay@ oregon.uoregon.edu Accepted for Publication: March 30, 2000.
} 
ties to share feelings about changes in their circumstances in a supportive environment.

Practice refers to specific training on a task to improve performance on that task. Practice may be a deliberate part of the therapy or it might be accomplished in the process of repeated administration of tests designed to determine amount of improvement. Practice alone might improve performance more generally if it results in transfer to tasks that have not been practiced.

Process training refers to a deliberate effort to employ a therapeutic program that would improve a wide range of tasks involving attention. For example, several studies have reported that Attention Process Therapy (APT) improves memory, learning, and some aspects of executive control (Mateer \& Sohlberg, 1988; Neimann, Ruff, \& Baser, 1990; Ruff, Baser, \& Johnson, 1989). Findings in a study by Sturm, Willmes, Orgass and Hartje (1997) also supported attention process training. They reported improved performance on neuropsychological tests specific to the type of attention trained. They further suggested that only patients with higher vigilance abilities respond to training involving more complex components of attention.

A recent study (Park, Roulx, \& Towers, 1999) compared performance on two neuropsychological tests (PASAT and Consonant Trigrams) in patients with brain injury who received APT and in normal controls. Both groups received the outcome measures twice, but the controls received no training. Results showed that the performance of the experimental group improved on both the neuropsychological measurements. The control group improved on one of the measures (PASAT) but not the other (Consonant Trigrams). The authors suggested that the cognitive processes involved in the consonant trigram are different than those stimulated by the training tasks in the APT, and concluded that the APT resulted in learning of new skills rather than improved processing.

Our study compares APT training with an educational and support method. We used ten neuropsychological tests to clarify changes that accompanied the interventions. We probed each of the major attentional networks (Posner \&
Petersen, 1990) together with working memory. In order to determine if the therapy improves the prospects of these patients in their normal everyday life, we also used a battery of questionnaires and structured interviews of the patients and in some cases their caregivers. Our research questions were: (1) How will APT compare with education in influencing the reports of patients and caregivers on patient performance in naturalistic settings? (2) Which brain networks will benefit the most from APT and/or education? (3) Will responses to APT and the information reveal insights about the effects of practice? (4) Will patients' responses to practice and/or APT differ based on their vigilance ability?

\section{METHOD}

\section{Research Design}

This study combined features of both between and within subject research methodology. It employed a basic crossover design using two groups. Participants were randomly assigned to groups. The groups were differentiated by the order of two blocks of treatment that they received. One treatment block (Condition A) consisted of the cognitive intervention, attention process training. The other block (Condition B) represented a placebo intervention consisting of brain injury education and supportive listening. Individuals in Group 1 participated in an A-B design while individuals in Group 2 participated in a B-A design.

During Condition A, participants received 24 hours of attention process training over 10 weeks as described under Independent Variables. During Condition B, participants received 10 hours of therapeutic support and education over 10 weeks that is also detailed in the Independent Variables section. Prior to beginning and following completion of each experimental condition, all participants were administered the following: (1) A neuropsychological attention battery; and (2) three questionnaires to assess perceptions of daily living. Furthermore, following each block of treatment, each individual participated in a structured interview. The sequence of experimental procedures is summarized in Figure 1.

In this design, each participant serves as a separate controlled single subject experiment. Additionally, the ability to compare performance on the probes for the seven participants in Group 1 with the seven participants in Group 2 after each treat- 
ment block provides a between group analysis. Comparing performance on probes of cognitive functioning and daily living abilities after each block of intervention reveals differences between the attention process training and the supportive counseling plus brain injury education.

\section{Participants}

Two groups consisting of 7 individuals with acquired brain injury were formed. Participants were referred by local service providers working with this population who had been given information about the study. The following subject selection criteria were utilized: (1) Between 18-60 years of age; (2) Acquired brain injury diagnosed at the time of injury with evidence on imaging studies; (3) Greater than one year post injury; (4) Absence from preinjury of any neurologic, psychiatric history, or learning disability; (5) Significant other available to take measures of everyday function; (6) Attention deficits determined via neuropsychological evaluation and subjective report from participant and/or significant other.

Demographic and injury related participant data are summarized in Table 1. The mean age of participants for Group One was 33.1 years (range 20 to 43 years) compared to a mean age of 38.1 years (range 19-50) for Group Two. Time post injury ranged from 1 to 22 years (mean 7.5 years) in Group One and 1 to 2.8 years (mean 1.6 years) in Group Two. All but one participant in each group suffered closed head injuries. The mean years of education for Group One was 11 years (range 9-16 years). For Group Two, the mean years of education was 12 (range 10-20 years). Both participants with technical training completed high school and were counted as having 13 years of education. In spite of random assignment, Group Two performed superiorly on the neuropsychological tests compared to Group One.

All of the participants were Caucasian with the exception of one participant in Group One who was Hispanic. All participants spoke English as a first language. Two individuals in each group were taking antidepressant medications during the time of the study. Two participants in Group One and one participant in Group Two were abusing alcohol or drugs at the time of injury. Length of substance use for all of these individuals was under five years. All participants and their significant others denied alcohol or drug use at the time of the study. Two participants in each group were scheduled to undergo litigation related to their injuries, although none of the cases were active during the time of the study.

\section{Experimental Materials}

Independent Variables

Condition A: The Attention Process Training program (APT) (Park, Proulx, \& Towers, 1999; Sohlberg, Johnson, Paule, Raskin, \& Mateer, 1994; Sohlberg \& Mateer, 1987) is a widely used cognitive rehabilitation program designed to remediate attention deficits in individuals with brain injury. The APT materials consist of a group of hierarchically organized tasks that exercise different components of attention commonly impaired after brain injury including sustained, selective, alternating, and divided attention. The program tasks place increasing demands on complex attentional control and working memory systems. Examples of exercises include auditory attention tapes such as listening for descending number sequences, alphabetizing words in an orally presented sentence, detecting targets with the presence of distracter noise or complex semantic categorization tasks requiring switching sets. A number of tasks combine auditory and visual activities. The training tasks were different than the neuropsychological tests, however, it is hypothesized that they utilize similar attentional circuits.

Participants received 24 hours of attention process training. Therapy was administered in three one-hour sessions each week over a total of ten weeks. Each participant was assigned a therapist who administered the attention process training program at a university speech and hearing clinic. Clinicians were either one of two certified speech/ language pathologists familiar with the APT program or one of five graduate students completing their master's degree in speech/language pathology. The student clinicians were closely supervised by a certified speech/language pathologist and were chosen because they had taken a graduate neurogenic course series that included a class on cognitive rehabilitation, had a minimum of 30 supervised hours with adult rehabilitation clients, and had completed an instructional program for using the APT materials. The APT tasks chosen for each client were specific to their attentional profile. For example, one participant completed very basic sustained attention tasks while another participant completed more complex sustained and alternating attention tasks.

Condition B: The therapeutic support condition consisted of a combination of brain injury education, supportive listening, and relaxation training. Materials were designed for this study. Participants selected their own education topics from a menu of choices related to neuroanatomy and neuropathology after closed head injury, cognitive 
Table 1. Injury and Demographic Information for each Participant.

\begin{tabular}{|c|c|c|c|c|c|c|}
\hline Participant & $\begin{array}{l}\text { Age at } \\
\text { injury }\end{array}$ & $\begin{array}{l}\text { Months post- } \\
\text { injury }\end{array}$ & Etiology & $\begin{array}{l}\text { Site(s) of } \\
\text { lesion }\end{array}$ & $\begin{array}{l}\text { Length of } \\
\text { coma/ } \\
\text { unconscious }\end{array}$ & $\begin{array}{c}\text { Education } \\
\text { level } \\
\text { prior to injury }\end{array}$ \\
\hline 1 & 18 & 12 & MVA & $\begin{array}{l}\text { B frontal; } \\
\text { L temporal; } \\
\text { R temporo- } \\
\text { parietal; } \\
\text { diffuse B } \\
\text { deep } \\
\text { white matter }\end{array}$ & 3.5 months & High school \\
\hline 2 & 18 & 26 & MVA & $\begin{array}{l}\text { Frontoparie- } \\
\text { tal }\end{array}$ & 11 days & Some college \\
\hline 3 & 25 & 29 & Anoxia & $\begin{array}{l}\text { Diffuse; } \\
\text { subcortical }\end{array}$ & 2 weeks & $\begin{array}{l}\text { College } \\
\text { graduate }\end{array}$ \\
\hline 4 & 49 & 15 & MVA & Frontal & 1 day & High school \\
\hline 5 & 15 & 33 & ATV & $\begin{array}{l}\text { Cerebellum; } \\
\text { brainstem }\end{array}$ & 3 weeks & $\begin{array}{l}\text { Some high } \\
\text { school }\end{array}$ \\
\hline 6 & 14 & 22.5 & MVA & $\begin{array}{l}\text { L temporo- } \\
\text { parietal }\end{array}$ & 7 months & Jr. high school \\
\hline 7 & 26 & 17 years & Motorcycle & $\begin{array}{l}\text { L fronto- } \\
\text { parietal }\end{array}$ & 2 months & High school \\
\hline 8 & 34 & 14 & Motorcycle & $\begin{array}{l}\mathrm{R} \text { fronto- } \\
\text { temporo- } \\
\text { parietal }\end{array}$ & 3 weeks & High school \\
\hline 9 & 49 & 12 & MVA & Frontal & $<1$ hour & High school \\
\hline 10 & 23 & 5 years & $\begin{array}{l}\text { MVA/ } \\
\text { pedestrian }\end{array}$ & $\begin{array}{l}\text { B frontal; B } \\
\text { basal ganglia }\end{array}$ & 6 weeks & $\begin{array}{l}\text { Technical } \\
\text { training }\end{array}$ \\
\hline 11 & 17 & 26 & Fall & $\begin{array}{l}\text { Occipital } \\
\text { with } \\
\text { frontal } \\
\text { involvement }\end{array}$ & $<1$ hour & High school \\
\hline 12 & 34 & 14 & $\begin{array}{l}\text { Cavernous } \\
\text { hemangiomma }\end{array}$ & L temporal & N/A & High school \\
\hline 13 & 42 & 13 & Motorcycle & Occipital & $<1$ hour & $\begin{array}{l}\text { Technical } \\
\text { school }\end{array}$ \\
\hline 14 & 44 & 26 & Fall & $\begin{array}{l}\text { Parietal- } \\
\text { occipital }\end{array}$ & 2 weeks & Prof. degree \\
\hline
\end{tabular}

disorders common after brain injury, relationship issues, and self advocacy and community reentry. There were written materials corresponding to each topic that were modified to match each participant's level of education and comprehension. Supportive listening consisted of a "check in" period asking participants, "How are things going?" and listening and paraphrasing responses. If participants initiated discussion of using compensatory strategies, these behaviors were verbally reinforced, but no specific support plan was initiated. Relaxation training consisted of teaching pro- gressive relaxation using basic breathing, muscle relaxation, and visualization exercises.

Sessions were conducted one hour per week for a total of ten weeks which matched the total number of weeks for the attention process training. Most sessions combined brain injury education (approximately a half hour) with supportive listening (15 minutes) and relaxation training (15 minutes). Occasionally participants wanted to spend the entire time period discussing an education topic of interest or using the supportive listening as an opportunity to share current life events. These 


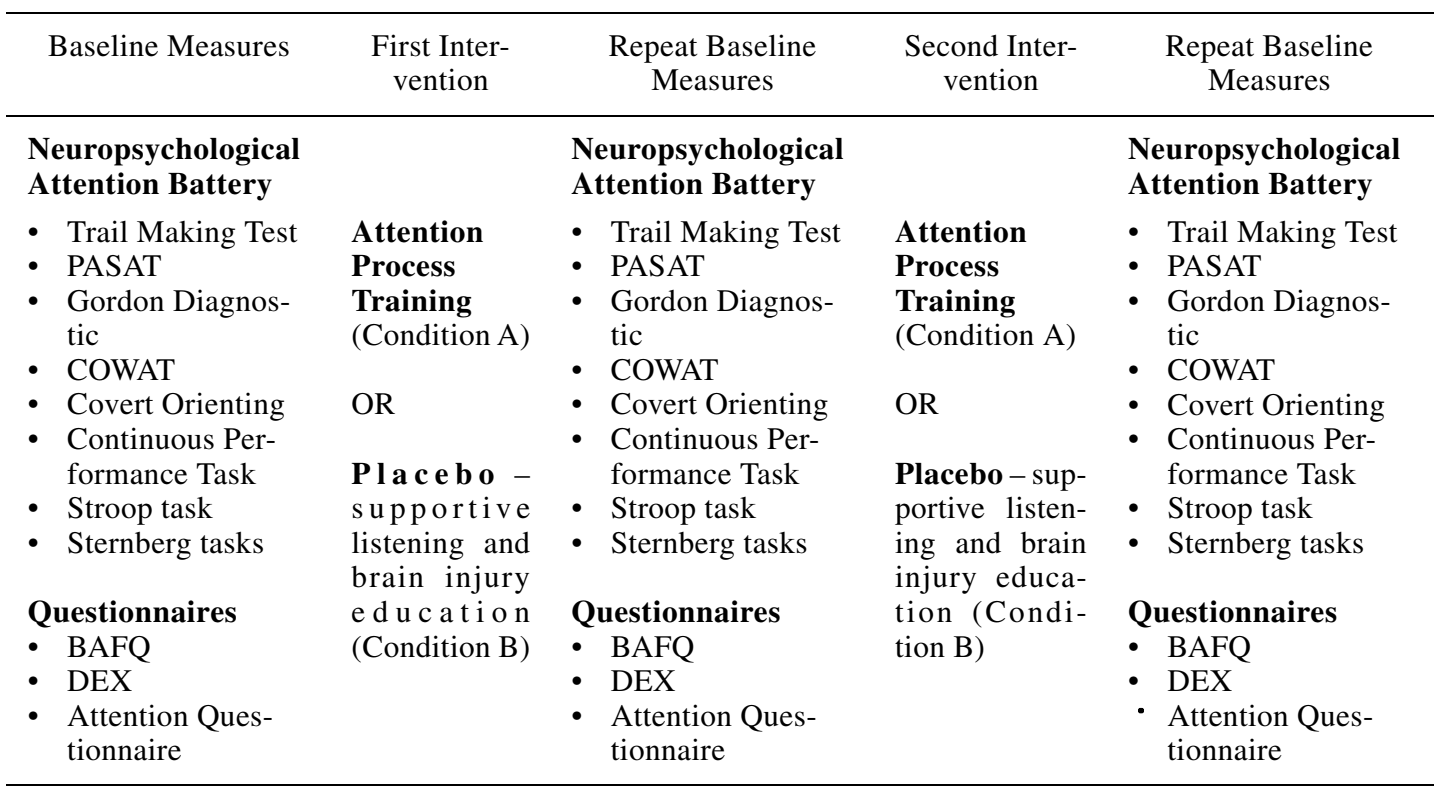

Fig. 1. Sequence of Experimental Procedures.

Note . PASAT $=$ Paced Serial Addition Task COWAT $=$ Controlled Oral Association Word Task; BAFQ = Brock Adaptive Functioning Questionnaire; DEX = Dysexecutive Questionnaire.

choices were permitted. The clinicians were the same as those described above. All clinicians completed training familiarizing them with the education and relaxation training materials and practicing supportive listening skills (e.g., paraphrasing).

\section{Dependent Variables}

Cognitive functions were measured using scores of standardized questionnaires, standardized and nonstandardized neuropsychological tests, and data from structured interviews. This section describes general methods for these dependent variables.

\section{Neuropsychological Tests}

The following neuropsychological tests were administered to each participant prior to and following completion of each experimental condition: (1) Trail Making Test (Reitan \& Wolfson, 1985); (2) Paced Auditory Serial Addition Task (PASAT; Gronwall, 1977); (3) Gordon Diagnostic Vigilance and Distraction (Gordon, 1986); (4) Controlled Oral Word Association Task (COWAT; Benton \& Hamsher, 1989); (5) Covert Orienting Task; (6) Stroop Task (Stroop, 1935); (7) Continuous Performance Tasks; (8) Memory for Location Task; and (9) Memory for Letters Task.

All of the tests were selected for their ease of administration and their sensitivity to attention impairments following brain injury. The first four neuropsychological tests were administered and scored by one of two board certified neuropsychologists with specialties in acquired brain injury or by a psychometrist trained and supervised by one of the two neuropsychologists. This portion of the battery took approximately one hour and was administered at the university speech and hearing clinic with a few exceptions when the test was administered at the office of one of the neuropsychologists. A clinical definition of attention impairment was adopted based upon the diagnosis of the neuropsychologist. Only participants whose performance on the attention battery resulted in a diagnosis of significant attention impairment were included.

The next five neuropsychological tasks were selected because there had been analysis of the corresponding brain circuitry using PET scans. They sampled the complex attentional circuitry identified in the literature including: (1) A sensory orienting network; (2) executive attention network; (3) vigilance network; and (4) working memory network (Kinsella, 1998; Posner \& Peterson, 1990). This testing was conducted in a cognitive laboratory at a university and lasted about three hours. The tasks were programmed in EGIS (Osgood, 1990) and presented on a Radius 20e com- 
puter monitor controlled by a Macintosh PowerPC 8500. (Electrical recordings of brain activity were collected during participant performance on these five neuropsychological tasks as well as on a group of normals. Results from this analysis are reported in a separate paper.)

A brief description of each of the neuropsychological tasks is given below. (Participant performance data for all of the neuropsychological tests are available upon request.)

\section{Trail Making Test}

This test assesses visual conceptual and visuomotor tracking. It includes two parts, A and B. In part A, participants are asked to draw lines to connect consecutively numbered circles; in part B, individuals are required to connect consecutively numbered circles and lettered circles by alternating between the two sequences. Trails B requires planning and working memory, both of which are clear executive functions and this measure is widely used to assess frontal lobe functions in clinical populations (e.g., Hanninen et al., 1997).

\section{The PASAT}

The PASAT is considered an information processing or attentional measure and is a sensitive index of cognitive impairment after brain damage. This test consists of a randomized presentation of a sequence of auditory digits. The patient is required to add each new digit to the digit immediately preceding it. Deary, Ebmeier, MacLeod, and Dougall (1994) examined brain activity during the PASAT using single photon emission computed tomography and found higher tracer intake in the right anterior and left posterior cingulate areas.

\section{Gordon Diagnostic System}

This measure is a computerized variation of the continuous performance task that is used to measure attention and self-control and to assess attention deficit disorders (Gordon \& Mettelman, 1988). We used two of the three GDS tests: The vigilance task and the distractibility task. The vigilance task measures the ability of an individual to focus and maintain attention over time and in the absence of feedback. A series of digits flash, one at a time, on an electronic display and the participant is told to press a button every time the digit 1 is followed by a 9 . The GDS records the number of correct responses, incorrect responses (commissions), and failure to respond to the target digit (omissions), and the average response time of correct responses. In the distractibility test, the same task is performed while irrelevant digits are flashed on either side of the column that display the target stimuli. A third test, the delay task, requires the participant to inhibit responding in order to earn points. Burg, Burright, and Donovick (1995) found that patients with TBI perform worse than normal controls on both the vigilance and distractibility tasks, but the two groups perform similarly on standard delay tasks.

\section{COWAT}

The COWAT is a measure of fluency in word production, a skill that is impaired after frontal lesions. This test consists of three word-naming trials. Patients are asked to produce as many words as they can beginning with a designated letter.

\section{The Stroop Task}

The Stroop task is a measure of conflict resolution and has been associated with activity in the anterior cingulate, which is a part of the executive attention network. The task used in our study was a variation of the Stroop test (Stroop, 1935), in which individuals were asked to name the ink color in which words were written and to ignore the word. There were color words (RED, YELLOW, BLUE, and GREEN) printed in four colors - yellow, green, blue, and red - and displayed against a gray background. There were also 72 non-color words. Participants were required to name aloud the color in which the word was written. The words could be: (a) Color-words identical to the color name (congruent condition), (b) color words different from the color name (incongruent condition), or (c) non-color words (neutral condition). Two participants were excluded from this task because they were color-blind.

\section{Covert Orienting Task}

In this task, participants had to detect the onset of an asterisk presented in the left or in the right visual field. The display consisted of two squares, one on the left and one on the right, that subtended $4.1^{\circ}$ of visual angle at the viewing distance of 60 $\mathrm{cm}$. Between the two boxes, a fixation dot was displayed and participants were asked to fixate on the dot. The cue appeared in the same position as the fixation dot and consisted of a cross, an arrow pointing to the left box, or an arrow pointing to the right box. The cue always subtended a visual angle of $.9^{\circ}$ in height and in width, at the viewing distance of $60 \mathrm{~cm}$.

\section{Continuous Performance Task}

In this task, a sequence of digits was presented and participants were asked to pay attention to the sequence and to press a key only after a four following an odd number. The digits were presented in 
the center of the monitor using the font Times, size 24 points, typeface bold. The trial started with a $200 \mathrm{~ms}$ blank followed by a digit that was displayed for $500 \mathrm{~ms}$. The time available for the response was $800 \mathrm{~ms}$ after non-target trials and 1,500 after target trials. The experiment consisted of 500 trials, divided in two 250-trial sessions. The stimulus was not a four (non-four non-targets) in 400 of the 500 trials, a four that followed an even digit (four non-targets) in 50 of the trials, and a four that followed an odd number (four targets) in 50 of the trials.

\section{Memory for Locations and Memory for Letters Tasks (Sternberg Tasks)}

The tasks included two sub-sessions, one in which the to-be-remembered stimuli were dot locations and the other in which the stimuli to be remembered were letters. The order of the two sub-sessions was counterbalanced across patients and experimental sessions.

In the locations task, a sequence of two or four black dots, displayed in different locations, was presented. Participants had to decide whether a red probe dot was in the same location as one of the two or four previously presented black dots. A $4.1^{\circ}$ squared box was displayed in the center of the monitor. Each dot could appear in one of eight possible locations on the imaginary circumference with a diameter of $9.1^{\circ}$ of visual angle (at the viewing distance of $60 \mathrm{~cm}$ ). The dots consisted of black or red circles subtending a visual angle of $.8^{\circ}$. The edge-to-edge distance between the dots and the central box was $1.9^{\circ}$.

Similarly, in the letter task, a sequence of two or four black letters was presented in the center of the screen and followed by a red probe letter. Participants had to decide whether the red probe was included in the previous set of two or four letters. The display consisted of a squared box, subtending a visual angle of $4.1^{\circ}$ at a viewing distance of 60 $\mathrm{cm}$. The letters appeared in the center of the box and were displayed in Times font, size 24 points, typeface bold. The stimulus set included 10 uppercase letters (A, D, I, L, M, Q, R, W, X, Y). Two patients were excluded from the two memory tasks because they were color-blind and could not distinguish the target items from the probe item.

\section{Questionnaires}

Three different questionnaires were used to evaluate adaptive functioning or the impact of attention deficits on day-to-day living. The three measures included: (1) The Attention Questionnaire (AQ; Sohlberg et al., 1994); (2) the Brock Adaptive Functioning Questionnaire (BAFQ; Dywan \&
Segalowitz, 1996) and (3) the Dysexecutive Questionnaire (DEX; Wilson, Alderman, Burgess, Emslie, \& Evans, 1996). These three measures were chosen because they were specifically developed for use with the brain injury population.

Each participant and a significant other was administered the three questionnaires at the beginning of the study and again following each experimental condition. Due to difficulties with reading, most of the participants were administered the questionnaires orally to check for question comprehension. The significant others filled out the questionnaires independently. A brief description of each of the questionnaires is provided below.

\section{Attention Questionnaire}

This questionnaire is based on Ponsford and Kinsella's (1988) attention questionnaire and asks the participant to rate frequency of occurrence for different attention problems. The attention problems are related to difficulty sustaining, switching, and dividing one's attention as well as dealing with distractions. This measure was selected because it is based on the model of attention used in the APT program and it samples a wide range of attention components. It also supplies a numerical indicator summarizing the overall frequency of perceived attention problems, which was helpful for comparing performance after the different treatment conditions.

\section{Brock Adaptive Functioning Questionnaire}

This questionnaire contains 68 items that were developed through clinical practice and with the help of community volunteers who had sustained brain injuries and their families. The goal of the BAFQ is to provide measures of adaptive functioning that are difficult to quantify psychometrically. It permits quantitative analysis of five domains of behavior: Planning, initiation, attention/memory, arousal/inhibition, and social monitoring. It supplies a significant other form and participant form. A pilot study looking at this tool suggested that a frontally generated electrophysiological response elicited during a simple attention task was strongly predictive of family and patient responses on the planning and initiation scales (Dywann \& Segalowitz, 1996). In addition, the questionnaire provides an index of awareness by finding the difference between significant other and self-ratings by the participant, with a higher score on the awareness index indicating poorer awareness on the part of the participant.

Dysexecutive Questionnaire

This questionnaire is a subtest of the Behavioral 
Assessment of Dysexecutive Syndrome (Wilson, et al., 1996). It contains 20 questions describing problems related to decreased attention and executive control which commonly occur following brain injury. The respondent rates each problem on a frequency of occurrence scale. There is a self and other rating form. This questionnaire generates a raw score ranging from 0 to 80 with a higher score reflecting greater deficits in executive function.

All participants endorsed some level of difficulty with attention on their responses to the questionnaires at the baseline measure. These subjective findings were consistent with objective findings showing decreased attention for all participants as measured by the neuropsychological tests. Formal analysis of the relationship between subjective and objective findings was not completed because the questionnaires are not standardized.

\section{Structured Interviews}

The fourteen participants completed a one-hour interview with one of the researchers following each 10-week block of treatment. Hence, each participant was interviewed twice, once following the attention process treatment and once following the brain injury education or placebo intervention. The participants were interviewed in the same clinical setting in which they had received their treatment. At the beginning of each interview, they were told that they were going to be asked to talk about their day- to-day functioning during the past several months when they had been coming to the clinic and working with their therapist. They were also told that the interview would be audio taped to provide the researchers with a record of what had been helpful and what could be improved in the therapy. The tape recorder was turned on and the participants were engaged in an interview that involved asking the following four questions: (1) Have you noticed anything in your day to day life that you feel has been affected by participating in the treatment here at the clinic? (2) Is there anything that you feel has been particularly helpful about coming to treatment? (3) Is there anything that has been disappointing about coming to treatment? (4) If you think specifically about changes in your thinking ability, how do you feel this treatment helped or did not help?

When possible, significant others were interviewed using the same questions to elicit their insights about the daily functioning of the person with brain injury. All but two individuals participated in interviews following each block of treatment. (Two were unable to recall having been involved in the treatment.) The audio taped interviews were transcribed and the transcripts were analyzed to develop a coding protocol that would facilitate the evaluation of response patterns. Results of this analysis suggested three areas in which individuals reported changes as a response to therapy. These included changes in (a) everyday functioning; (b) psychosocial functioning; and (c) cognitive functioning. Each of these three areas was further divided into a variety of categories again derived from the content of the interviews. Examples of categories in the everyday functioning area included improved leisure time management and improved performance in school. (A stringent definition was used for the category of everyday functioning as it was reserved for reports of consistent change in a skill that influenced performance in work, home, school, or community. For example, in order to be coded as a change in everyday functioning, the participant would need to report "I am now cooking dinners" versus "I cooked dinner last night".) The categories in the psychosocial domain that were mentioned in the interviews included improved emotional well-being and confidence and understanding of issues related to the brain injury. All of the categories in the third domain, cognition, pertained to memory, attention, and executive functions. A fourth category of response codes was also developed to document reports of disappointment or concerns about the intervention.

Each protocol had a space for recording statements of changes related to treatment that was tied to a specific behavior in a particular context. Examples of recorded comments included "I noticed that I can sit through a whole movie now"; or "He is initiating more conversations at the dinner table". These comments are summarized in the appendix.

The coding instructions included reading the interview transcript, checking any category on the protocol that was noted in the interview, and recording any specific behavioral examples. Categories were designed to be mutually exclusive, thus a person would not check the "improved prospective memory" category and the "general improvement in memory" category in response to the same comment. Also, a category could only be marked once to control for differences in the verbosity and openness of the participants. Hence, even if a participant gave several examples of improved working memory, this category would only be marked one time on the protocol.

To check reliability, a blind coder who was naive to the study and a practitioner in the community with no involvement with the participants read five of the interviews and completed the coding sheets. The data were analyzed by looking at the 
number and types of categories coded across participants in addition to looking at the narrative comments following their attention process training and their placebo treatment.

\section{RESULTS}

The results are organized in two sections. In the first section, we examine evidence for general improvements specific to the two interventions. We first use a subjective measure of improvement which is the number and type of changes reported during the structured interview. Because this measure shows a strong dissociation between cognitive performance and psychosocial function, we then examine the relationship between the self-reports of cognitive changes and an objective measure of performance, the PASAT. The PASAT was chosen because the literature suggests it is particularly sensitive to the effects of brain injury, it is a commonly used instrument with this population, and the test involves different functions including executive control, sustained attention, and working memory (Sherman, Strauss, \& Spellacy, 1997).

In the second section, we attempt to identify brain networks that appear sensitive to the effects of APT. We used the results of neuropsychological testing that were performed by patients in the pretest session, after the first intervention, and after the second intervention. The same tests were administered three times, hence any changes in performance could be the result of practice effects. To tease out the effect of repeated practice from the effect of intervention, we performed two different analyses. The first analysis looked at test performance across the three sessions, regardless of type of intervention. A main effect of practice in this analysis would be demonstrated by improved patient performance across sessions, regardless of the type of intervention. The second analysis examined the specific effect of intervention. In this analysis we used difference scores between performance at the start of a particular type of intervention and performance after the relevant intervention. These improvement scores were analyzed as a function of intervention (APT and brain injury education) and order (APT first versus brain injury education first). A main effect of order would indicate a difference between the two groups of patients. A differential improvement after the two interventions regardless of practice would suggest a significant effect of intervention.

In these analyses, we also examine the effect of vigilance level on both practice effects and intervention effects. The purpose of examining vigilance is to evaluate Sturm et al.'s (1997) suggestion that a high vigilance level is a prerequisite for improvement in other cognitive domains.

\section{Intervention Effects on Behavior}

All members of the sample participated in interviews at the end of each intervention, but two were unable to recall having been involved in the treatment, thus 12 participants contributed interview data (as opposed to 14 participants for the neuropsychological and questionnaire data). The interview addressed two questions. First, are there quantitative and/or qualitative differences in the changes reported by participants after APT and after brain injury education? Second, is there a relationship between reported changes and cognitive improvement measured by an objective test of cognitive performance (PASAT)?

The first question was addressed by analyzing the number of changes reported in the interview as a function of intervention (brain injury education and APT) and type of change (everyday functions, memory/attention, psychosocial functions). The second question was addressed by dividing the patients in two groups on the basis of the number of cognitive changes reported (2 or less and more than 2) and analyzing improvement of PASAT scores in the two groups.

Reliability between the two coders (naive coder and a researcher) was assessed by computing point by point agreement ratios (Kazdin, 1982) for the codes given to each independent statement in the transcripts for the five randomly selected transcripts. The ratios ranged from 73 to 85 percent, indicating adequate reliability. Areas of most frequent disagreement were in the cognitive domain between prospective memory 
Table 2 . Means and Standard Deviations for all Participants.

TRAIL MAKING (Time to complete in seconds)

\begin{tabular}{|c|c|c|c|c|c|c|}
\hline \multicolumn{3}{|c|}{ Trails A } & \multicolumn{4}{|c|}{ Trails B } \\
\hline First & Second & Third & First & Second & \multicolumn{2}{|c|}{ Third } \\
\hline$M \quad(S D)$ & $M \quad(S D)$ & $M \quad(S D)$ & $M \quad(S D)$ & $M \quad(S D)$ & $M$ & $(S D$ \\
\hline $41.9 \quad(17.9)$ & $44.2 \quad(28.1)$ & $43.8 \quad(24.6)$ & $125.3 \quad(78.3)$ & $114.9 \quad(62.9)$ & 92.1 & $(34.7)$ \\
\hline \multicolumn{7}{|c|}{ PASAT (Number correct) } \\
\hline \multicolumn{3}{|c|}{ Slow Trial } & \multicolumn{4}{|c|}{ Fast Trial } \\
\hline First & Second & Third & First & Second & \multicolumn{2}{|c|}{ Third } \\
\hline$M \quad(S D)$ & $M \quad(S D)$ & $(S D)$ & $(S D)$ & $(S D)$ & $M$ & $(S D)$ \\
\hline $26.2 \quad(11.7)$ & $30.4 \quad(13.7)$ & $33.3 \quad(13.3)$ & $24.1 \quad(10.7)$ & $26.9 \quad(11.0)$ & 30.0 & $(12.5)$ \\
\hline
\end{tabular}

Note. PASAT $=$ Paced Auditory Serial Addition Task.

GORDON DIAGNOSTIC SYSTEM (Number correct)

\begin{tabular}{|c|c|c|c|c|c|c|c|c|c|c|c|}
\hline \multicolumn{6}{|c|}{ Vigilance Task } & \multicolumn{6}{|c|}{ Distraction Task } \\
\hline \multicolumn{2}{|c|}{ First } & \multicolumn{2}{|c|}{ Second } & \multicolumn{2}{|c|}{ Third } & \multicolumn{2}{|c|}{ First } & \multicolumn{2}{|c|}{ Second } & \multicolumn{2}{|c|}{ Third } \\
\hline$M$ & $(S D)$ & $M$ & $(S D)$ & $M$ & $(S D)$ & & $(S D)$ & $M$ & $(S D)$ & $M$ & $(S D)$ \\
\hline 26.1 & $(7.2)$ & 26.8 & $(6.5)$ & 27.9 & $(3.2)$ & 16.7 & $(10.8)$ & 22.0 & $(10.3)$ & 21.6 & $(10.4)$ \\
\hline \multicolumn{12}{|c|}{ COWAT (Total Scores) } \\
\hline \multicolumn{3}{|c|}{ First } & & \multicolumn{4}{|c|}{ Second } & & \multicolumn{3}{|c|}{ Third } \\
\hline & & $(S D)$ & & & $M$ & $(S$ & & & $M$ & & $(S D)$ \\
\hline & & 9.6 & & & 28.0 & 9 & & & 30.0 & & 12.4 \\
\hline
\end{tabular}

Note. COWAT $=$ Controlled Oral Word Association Task.

and working memory, and in the psychosocial domain between improved awareness and improved sense of well-being.

\section{Number and Types of Changes as a Function of Intervention}

This analysis revealed a significant effect of intervention, $F(1,10)=5.00, M S E=.37, p<.05$, indicating that the number of changes reported after APT was greater than the number of changes reported after brain injury education (.91 and .58 , respectively). The effect of type of change was significant, $F(2,20)=19.35, M S E=$
$9.42, p<.0001$, indicating that a greater number of changes were reported in memory and attention (1.59) than in psychosocial functions (.59); the smallest number of changes was reported in everyday functions (.05). The type of change $\mathrm{X}$ intervention interaction was also significant, $F(2,20)=10.16, M S E=9.42, p<.001$. Although the distributions of reported changes are not likely to be normal, the interaction is large enough to support parametric analyses. More changes were reported in the memory/attention category after APT than after brain injury education, whereas more psychosocial changes 
were reported after brain injury education than after APT (see Fig. 2). This result is particularly interesting, because it suggests that APT is specifically associated with perceived changes in cognitive functions rather than psychosocial variables, whereas the opposite seems to be true for the brain injury education intervention.

\section{Relationship Between Perception and Perfor- mance}

For each participant we computed the difference between the PASAT test scores from the first and third sessions. We divided patients in two groups, patients who reported a total of $0-2 \mathrm{cog}$ nitive changes in the structured interviews and patients that reported more than 2 cognitive changes. Patients who reported more than 2 changes had a greater change in PASAT scores than patients that reported fewer than 2 changes (9.1 and 3.1, respectively). A test showed that this difference was significant, $t(12)=-2.36, p$ $<.05$. This result indicates that perceived cognitive improvement in the structured interview corresponds to greater improvement in the
PASAT, an objective measure of cognitive functions.

Data from significant others were only gathered for eight participants. Due to the small numbers, these data were not analyzed. The status of six significant others changed such that the person did not participate in post treatment interviews and questionnaires. (Attrition was due to significant others experiencing the onset of a medical condition, moving, or feeling too overwhelmed to participate. Additionally, one participant moved out to a more independent residence and the significant other did not want further involvement in caring for this person.)

From an ecological perspective, it is interesting to compare the narrative comments following each of the interventions as shown in the appendix. Only after APT did participants and their significant others provide any examples of behaviors specifically related to improved working memory. Reported "disappointments" in the therapy related to logistics in coming to the clinic (e.g., problems with the taxi or bus; 3 participants); wishing the therapy would continue

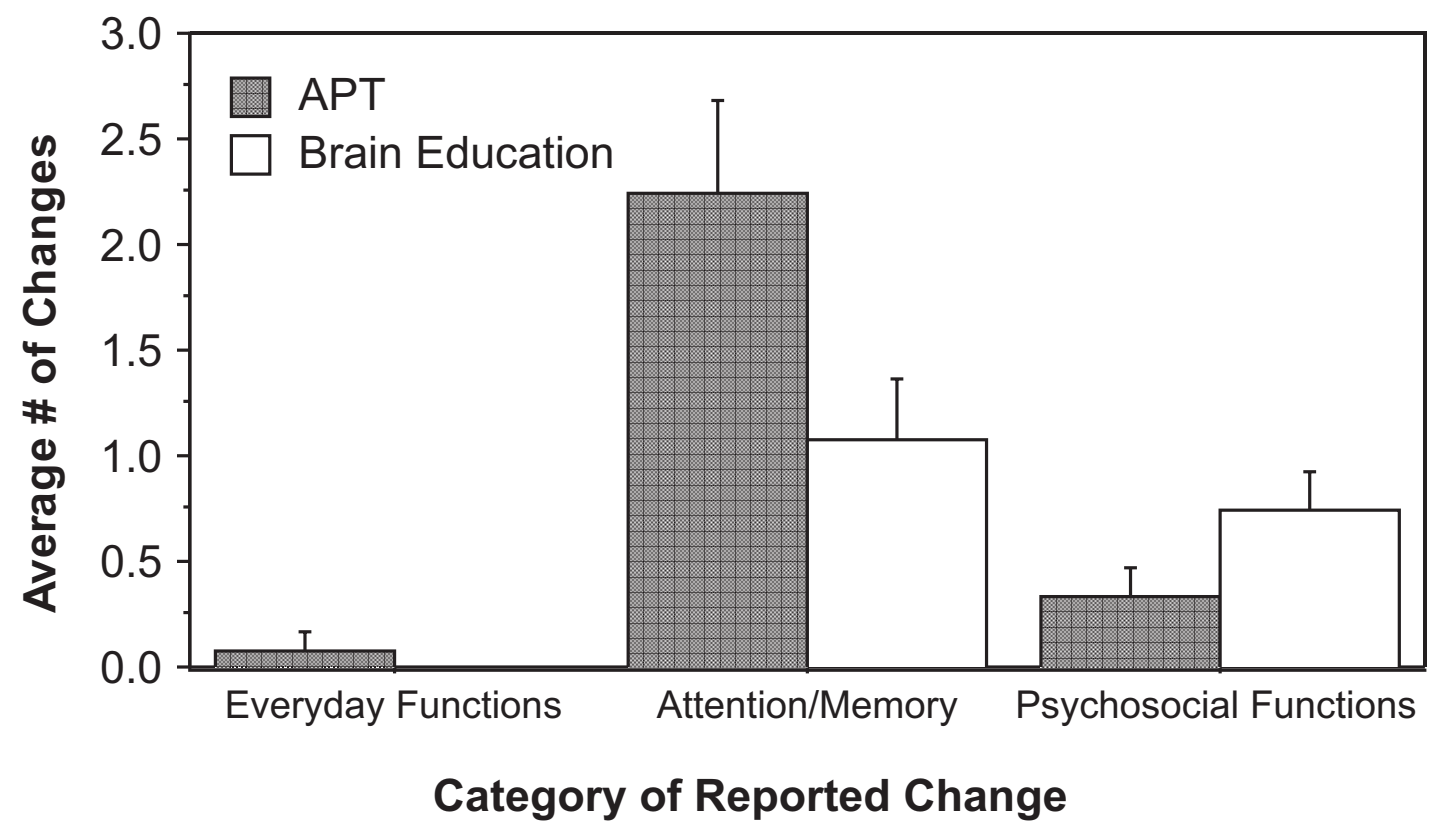

Fig. 2. Number of changes reported in the structured interview as a function of category (everyday functions, memory/attention, and psychosocial functions) and treatment (APT and Brain Education). The bars indicate one standard error. 
for longer (2 participants, one after APT and one after brain injury education) and frustrations about not working directly on "getting back to work" (2 participants, one after APT and one after brain injury education).

\section{Effect of APT on Attentional Networks}

This section examines the effect of APT on changes in cognitive functions mediated by different brain networks. We consider first tasks that either measure directly or involve components of the high-level executive attention network. These include the PASAT, Stroop, Trails B, COWAT, and Working Memory tasks. Next we examine the orienting and vigilance networks. In these analyses we examined the effect of practice (changes in test performance with repeated administration), the effect of the type of intervention, and their interaction with vigilance level. Our purpose was to examine (1) whether patients improve by repeating the tests and/or by undergoing cognitive training; and (2) whether patients with high and low vigilance levels differ in their improvement due to practice and/or APT.

In all the following analyses, patients were divided into a low vigilance or a high vigilance group depending on their score on the vigilance task of the Gordon Diagnostic System (GDS) in the pretest session. High vigilance patients had a score of 29 or higher $(n=8)$ and low vigilance patients had a score of 28 or lower $(n=6)$.

\section{Executive Network}

\section{PASAT}

As described, the PASAT is a sensitive measure for detecting changes in cognitive functions after cognitive intervention. We analyzed PASAT test scores in two ANOVAs investigating the effect of practice and the effect of type of intervention (APT and brain injury education). A three-way repeated measures ANOVA analyzed the effect of practice (first, second, and third session), trial (slow and fast), and vigilance level (low and high). The analysis revealed a significant effect of vigilance, $F(1,12)=11.60$, $M S e=432.20, p<.01$. High-vigilance patients had higher scores on the PASAT than low-vigi- lance patients (35.2 and 19.6, respectively). The effect of trial was also significant, $F(1,12)=$ $4.71, M S e=30.70, p=.05$. As expected, scores were higher in the slow trial than in the fast trial (29.90 and 27.0, respectively). Practice was significant, $F(1,12)=12.24, M S e=19.80, p<$ .0003 , and significantly interacted with vigilance level, $F(1,12)=5.50, p<.02$. High-vigilance patients showed greater improvement across sessions $(30.0,35.60$, and 39.90 in the first, second, and third sessions, respectively) than low-vigilance patients $(18.70,19.30$, and 20.70 in the first, second, and third sessions, respectively).

The effect of intervention was analyzed using improvement scores as dependent variables. The four-way mixed ANOVA examined the effect of the between-subjects factors, order (APT first and brain injury education first) and vigilance level (low and high) and the two within-subjects factors, intervention (APT and brain injury education) and trial. Only two effects reached significance in this analysis. Vigilance level was significant, $F(1,10)=15.39, M S e=15.22, p<$ .003 . High-vigilance patients showed a greater improvement than low-vigilance patients (4.9 and 1.0 , respectively). More importantly, the effect of intervention was significant, $F(1,10)=$ $4.96, M S e=58.80, p=.05$. This effect indicates that improvement in PASAT scores were always greater after APT than after brain education. This effect did not interact with vigilance level, $F(1,10)<1$, indicating that both groups of patients benefited more from APT than from brain education.

These results indicated that patients improved in PASAT performance across sessions. More importantly, in each session, improvement after APT was greater than improvement after brain injury education, suggesting that APT had a specific effect on the cognitive functions measured by the PASAT. Performance on the PASAT depended on the vigilance level of the patients: Patients with a higher vigilance level had higher PASAT scores and showed a greater improvement across sessions. However, both groups of patients benefited more from APT than from brain injury education. 


\section{Stroop and Trails $B$}

The Stroop task and Trails B, both dependent upon executive networks, showed a similar improvement with practice and therefore were analyzed together. In the Stroop task, we used error interference (errors in the congruent condition minus errors in the incongruent condition). Performance in Trails B was measured as a difference in time between Trails A and Trails B. We analyzed the data of these two tasks in the same ANOVAs. To obtain comparable measures, we transformed both the raw scores and the improvement scores into rank values (larger values indicate better performance, Whyte et al., 1997). Only 12 participants were included in these analyses. Two participants were color blind and could not perform the Stroop task; one of these two participants was not able to complete Trails B.

Only two effects reached significance in the second analysis: The main effect of treatment, $F(1,8)=12.63, M S e=39.50, p<.01$, and treatment $\times$ vigilance level interaction, $F(1,8)=$ $8.23, M S e=39.50, p<.03$. Figure 3 shows the two-way interaction. Patients in the high vigilance group did not show any difference between improvement after APT and improvement after brain education. Patients with low vigilance scores, however, showed a pattern similar to the PASAT analysis. Improvement was greater after APT than after brain education both in the second and the third testing sessions. ${ }^{1}$

These results indicate that high-vigilance patients perform better than low-vigilance patients, but that vigilance does not influence practice. However, vigilance does influence the effect of intervention: Only patients with low vigilance scores benefit more from APT than brain education.

\section{Working Memory}

Performance in working memory tasks are frequently related to executive control measures

\footnotetext{
${ }^{1}$ A MANOVA computed on non-transformed scores of the two measures gave similar results. In particular, both the order $\mathrm{X}$ session and the order $\mathrm{X}$ session $\mathrm{X}$ vigilance interaction were significant in the analysis examining the effect of intervention.
}

(Smith, 1999). Accordingly, we included performance on our two working memory tasks, memory for letters and memory for locations. Two participants did not perform the Sternberg memory tasks because they were color-blind and could not distinguish the target items from the probe item. In this task, performance was measured as percentage of errors. Two separate analyses were carried out on the letter task and on the location task. The dependent measure was improvement in the error percentage scores between first and second session and between second and third session. The independent measures were order (APT first and brain injury education first), vigilance level (low and high), and session. None of the effects were significant in the letter task analysis, indicating that in this task there was a similar improvement in the second and the third session, and no difference between APT and brain injury education interventions.

In the location task, however, there was a significant order $\times$ session interaction, $F(1,8)=$ 5.97, Mse $=133.36, p<.05$, indicating that improvement from the previous session was greater after APT than after brain education ( $10.8 \%$ and $3.4 \%$, respectively).

This result indicates that APT had a specific effect on working memory for location. Accuracy on this task improved more after APT than after brain injury education in both the second and the third sessions. ${ }^{1}$

\section{COWAT}

The COWAT, also a measure of frontal functions, was analyzed for the effect of practice by using a two-way mixed ANOVA that examined the effect of vigilance level (high and low) and practice (first, second, and third session). COWAT scores served as the dependent measure.

COWAT scores were influenced by the vigilance level, $F(1,10)=11.88$, Mse $=172.27, p<$ .01. Patients with higher vigilance scores had higher COWAT scores than patients with low vigilance scores (34.4 and 19.6 respectively). The effect of practice approached significance, $F(2,20)=3.47$, Mse $=11.22, p=.05$, indicating a slight increase in performance across sessions 

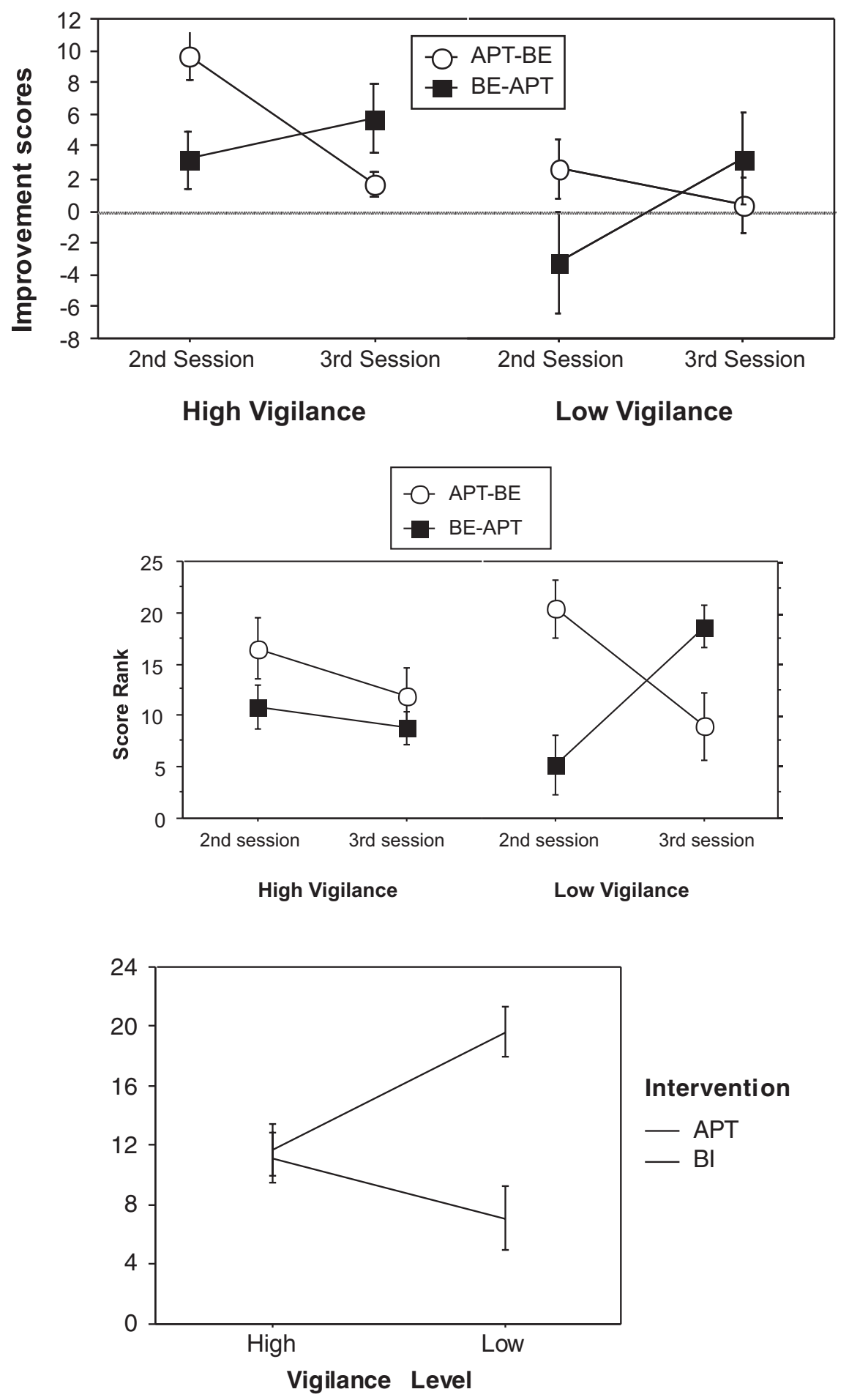

Fig. 3. Improvement on Stroop and Trails B-A scores as a function of intervention (APT and Brain Education), order (APT-Brain Education and Brain Education-APT), and vigilance level. Improvement is measured in score ranks. The bars indicate one standard error. 
(26.10, 28.0, and 30.0 for sessions one, two, and three respectively). However, the analysis of COWAT improvement scores did not show any significant effect. In particular, improvement was not influenced by intervention.

These results indicate a difference between COWAT and other tests associated with frontal functions. Although participants show a slight improvement in COWAT scores as a function of repeated testing, improvement was not influenced by intervention, $F(1,10)<1$.

\section{Summary}

Overall there were improvements in performance with practice for all of these tasks except memory for letters. For PASAT, Stroop, Trails, and memory for locations there were also specific improvements in performance associated with APT that were greater than those associated with brain injury education. In the case of Stroop and Trails, the specific improvement with APT was limited to low vigilance performers.

\section{Vigilance Network}

A MANOVA was carried out on three measures of vigilance (number of hits on the Gordon Vigilance task, Gordon Distractibility task, and CPT) as a function of practice (first, second, and third session). In this analysis, the dependent variable was number of hits. The analysis revealed a significant effect of practice, $F(6,50)=2.32, p<$ .05 , indicating a progressive improvement of performance across sessions. Average vigilance scores were $21.70,23.90$, and 24.80 for first, second, and third session, respectively.

A second analysis was carried out on improvement scores in the second and third sessions and examined the effect of order and treatment. None of the effects were significant. In particular, the effect of treatment was far from significant, $F(3,10)<1, p>.65$, indicating that intervention did not influence vigilance improvement on these tasks.

These results show that performance on these three vigilance tasks improved across sessions, but improvement was similar after APT and after brain education. Therefore, APT did not seem to have any specific effect on the vigilance performance of patients with TBI.

\section{Orienting Network}

The validity effect on the covert orienting task (valid minus invalid trials) and times on the Trails A of the Trail Making Test were used as measures of visuo-spatial orienting abilities. Two MANOVAs carried out on these measures did not show any effects of practice or intervention. Therefore, there is no evidence in these data of an improvement in performance across sessions or of a specific benefit of APT.

\section{Questionnaires}

A multivariate analysis of the three questionnaire scores (Attention questionnaire, DEX, and BROCK) showed a significant effect of practice (improvement in reports of functioning over time), $F(6,50)=3.36, p<.01$. However, there was not significant interaction between session and order, $F(3,8)<1, p>.65$, indicating that improvement in the response to the questionnaires was not differentially influenced by the type of intervention. (Due to attrition in the significant others, their questionnaire data were not analyzed.)

\section{DISCUSSION}

\section{Research Questions}

The results of this rather small-scale study provide support for differential effects of therapeutic strategies in the rehabilitation of patients with acquired brain injury. All aspects of the study suggest that practice, whether by repeating the assessment tasks, or from participating in the training of general processes using APT, improves performance. In addition, teaching about brain injury issues appears to improve the attitude of patients.

The first research question focused on comparing the effects of attention process training with brain injury education. APT seems to improve performance on a wide range of tasks that involve executive functions and attentional control. Because the tasks used in the APT were 
different from the neuropsychological tests used to assess cognitive functions, improvement on those tests represents a generalization of learning. These findings are consistent with other evaluations of attention process training which suggest that associated cognitive changes are not caused by simple nonspecific cognitive stimulation (e.g., Neimann, et al., 1990; Sohlberg \& Mateer, 1989; Sturm, et al., 1997; Wood \& Fussey, 1987).

Subjective patient report from structured interviews also suggests a positive effect of APT on executive control and working memory. Patients reported more changes in cognitive function following APT and more changes in psychosocial functioning following the brain injury education. Those who reported more cognitive changes also had greater improvements on the PASAT.

The second question was to explore which brain networks would benefit the most from intervention. The improvement due to APT in our study appears to be confined to tasks that draw on executive function and is not present in tasks involving mainly vigilance or mainly orienting toward sensory signals. Again, this is consistent with other reports showing effects of attention process training. Similar to our study, Park et al. (1999) reported improvements on a working memory task, consonant trigrams, which was specific to attention process training. It is not known in that study whether improvements on the PASAT for the head injury group who received APT were due to practice, APT, or a combination of the two since the normal control group who were given the PASAT twice without any intervention showed a practice effect on serial administration of the PASAT.

In a separate study of our same patients (Pavese, Heidrich, Sohlberg, McLaughlin, \& Posner, 1999), we found clear evidence of impairment in the ability to control stimulus input in the Stroop task. Normal participants showed a difference between neutral and color word trials over electrodes that appear to involve anterior cingulate activation. This was missing in the patient population. Additional comparisons between patients and normals indicated difficulty in communicating information between brain areas. We speculate that the repetitive training in APT might help to restore some of these control mechanisms.

The third and fourth research questions focused on the role of practice and the role of patient vigilance levels. We found interesting differences in test practice and intervention effects in high- and low-vigilance patients extending Sturm et al.'s (1997) findings. The significant finding in this study was that for low-vigilance participants, APT resulted in improved attentional skills, which generalized to measures that were different from the training tasks. The study also showed that for the more demanding attentional (or working memory) activity required by the PASAT, the treatment effect was also apparent for less impaired (high vigilance) participants.

An important clinical implication of this study is the encouragement to use structured interview to ascertain how attention is employed in day-to-day life. Although the indices provided by the standardized questionnaires and neuropsychological tests gave a quantitative marker for the level of impact on daily life produced by the attention deficits, they did not provide specific information on the nature of the impact. This information was only revealed through the interview. For example, a number of participants showed no response to treatment as measured by the questionnaires, but when interviewed spontaneously gave examples such as "I can watch a whole movie", "I can drive and listen to the radio", and "I can remember phone numbers". Perhaps due to the concrete nature of their thinking, the participants did not note changes unless they were asked about a specific activity with relevance to their lives.

The fundamental shortcoming of the commonly employed questionnaires, checklists, and rating scales is that they do not produce authentic data; rather, they give an indication of different individuals' perceptions of functioning. An alternative assessment paradigm that offers a model for ecological measurement of real world functioning is the functional assessment model used in special education to assess children who are displaying severe behavioral problems (Lucyshin, Albin, \& Nixon, 1997; O’Neill, Hor- 
ner, Albin, Storey, \& Sprague, 1990). This model allows individuals and caregivers to generate and test hypotheses about the contexts surrounding problem behaviors. Another relevant assessment model is the Communication Profiling System, which uses interpretive research methods to evaluate the impact of a communication impairment (i.e., the communication handicap) on an individual's daily life (SimmonsMackie \& Damico, 1996). Cognitive rehabilitation may benefit from exploration of such measurement paradigms.

In addition to encouraging the use of structured interview in the assessment of attention, this study supports Kinsella's (1998) call for improvement of formal measures of attention. Participants performed differently on the various attention tests. Kinsella (1998) notes the difficulty of using neuropsychological measures that are multifactorial and calls for standardized measures to evaluate discrete components of attention. She further calls for more analyses of the relationship between psychological tests and theoretical constructs of attention in order to improve assessment.

\section{Future Studies}

Knowledge gained from this study helps set the stage for future inquiries. One important area of consideration for future investigations concerns the formation of participant groups. Larger numbers of participants, the use of a control group, and matching participants would strengthen the study. A control group that receives serial measurements without any treatment would enhance experimental control. Furthermore, in our study, the two groups were not matched for important demographics such as education and may have responded differentially to the treatment. Additionally, follow up measures would strengthen our understanding of intervention effects. We recognize that the complexity of this population including the difficulties in identifying matched controls and the required length of time to study intervention effects creates challenges for making these improvements in methodology.

Future studies would further benefit from using clinicians who were blind to the study design and participant group assignment. Although every effort was made to follow the objective experimental protocol, the current study may have introduced an experimental bias effect by having the authors provide some of the intervention. Ultimately, replication of findings will be the test of cognitive treatment effects.

This study encourages looking at specific patient profiles in order to predict who may be most responsive to practice and/or attention training. Further investigation of whether vigilance levels affect responsiveness to intervention is warranted. Investigation of other variables such as IQ and educational background may also be enlightening.

The current study employed an existing rehabilitation program that is loosely based on a theoretical attention hierarchy and used selected neuropsychological tests and cognitive marker tasks to measure different aspects of attention. An advantage of this approach was that we could look at a wide range of possible effects. The disadvantage of this approach, however, is that there may have been enhanced treatment effects if the materials and assessments were generated from the same theoretical framework. Having completed this initial broad study of possible attention training effects, future investigations might benefit from closer linkage between the rehabilitation materials and the assessment tools. For example, a series of separate studies that evaluate training of discrete attention networks might be revealing.

\section{REFERENCES}

Awh, E., Smith, E.E., \& Jonides, J. (I995). Human rehearsal processes and the frontal lobes: PET evidence. In J. Grafman, K.J. Holyoak, \& F. Boller (Eds.), Structure and functions of the human prefrontal cortex, (Vol. 769, pp. 97-I I 7). New York: Annals of the New York Academy of Sciences.

Ben-Yishay, Y., Piasetsky, E.B., \& Rattock, J. ( 1987 ). A systematic method for ameliorating disorders of basic attention. In M.J. Meyer, A.L. Menton, \& L. Diller (Eds.), Neuropsychological Rehabilitation . Edinburgh: Churchill Livingstone.

Benton, A.L., \& Hamsher, K.D. (I989). Multilingual aphasia examination. Iowa City, Iowa: AJA Associates. 
Brittain, J.L., la Marche, J.A., Reeder, K.P., Roth, D.L., \& et al. (I99I). Effects of age and IQ on Paced Auditory Serial Addition Task (PASAT) performance. Clinical Neuropsychologist, 5(2), I63-I 75 .

Burg, J.S., Burright, R.G., \& Donovick, P.J. (I995). Performance data for traumatic brain-injured subjects on the Gordon Diagnostic System (GDS) tests of attention. Brain Injury, 9(4), 395-403.

Cabeza, R., \& Nyberg, L. ( I 997). Imaging cognition: An empirical review of PET studies with normal subjects. Journal of Cognitive Neuroscience, 9(I), I-26.

Cohen, R.A. (I 993). The Neuropsychology of Attention. New York: Plenum Press.

Corbetta, M., Meizin, S., Dobmeyer, S., Shulman, G.L., \& Petersen, S.E. (I 993). A PET study of visual spatial attention. Journal of Neuroscience, I3, I 202-I 226.

Crawford, J.R., Obonsawin, M.C., \& Allan, K.M. (I998). PASAT and components of WAIS-R performance: Convergent and discriminant validity. Neuropsychological Rehabilitation, 8(3), 255-272.

Deary, I.J., Ebmeier, K.P., MacLeod, K.M., \& Dougall, N. (I994). PASAT performance and the pattern of uptake of -super( $99 \mathrm{~m}$ )Tc-exametazime in brain estimated with single photon emission tomography. Biological Psychology, 38( I), I-I 8.

Deary, I.J., Langan, S.J., Hepburn, D.A., \& Frier, B.M. (I 99I). Which abilities does the PASAT test? Personality \& Individual Differences, I2(I0), 983987.

Diener, D. (1988). Absence of the set-size effect in memory-search tasks in the absence of a preprobe delay. Memory \& Cognition, I6, 367-376.

DiGirolamo, G.J., Heidrich, A., Posner, M.I., Similar time course and neural circuitry across congruent and incongruent Stroop conditions, submitted.

Diller, L., Ben-Yishay, Y., Gerstman, L.J., Goodkin, R., Gordon, W., \& Weinberg, J. ( I974). Studies of cognition and rehabilitation in hemiplegia, Rehabilitation Monograph No. 50 . New York: NYU Medical Center.

Dywan, J., \& Segalowitz, S.J. (I996). Self and family ratings of adaptive behavior after traumatic brain injury: psychometric scores and frontally generated ERPs. Journal of Head Trauma Rehabilitation, II (2), 79-95.

Egan, V. (I988). PASAT: Observed correlations with IQ. Personality \& Individual Differences, 9(I), I79-I 80 .

Gordon, M. (I986). How is a computerized attention test used in the diagnosis of attention deficit disorder? Journal of Children in a Contemporary Society, I9( I-2), 53-64.

Gordon, M., \& Mettelman, B.B. (I988). The assessment of attention: I. Standardization and reliability of a behavior-based measure. Journal of Clinical Psychology, 44(5), 682-690.
Gray, J.M., Robertson, I., Pentland, B., \& Anderson, S. (I 992). Microcomputer-based attentional retraining after brain damage: A randomized group controlled trial. Neuropsychological Rehabilitation, 2, 97-I I 5 .

Gronwall, D.M. (I 977). Paced auditory serial-addition task: A measure of recovery from concussion. Perceptual \& Motor Skills, 44(2), 367-373.

Gronwall, D. (I98I). Minor head injury. Neuropsychology, 5, 253-265.

Gronwall, D. (1987). Advances in the assessment of attention and information processing after head injury. In H.S. Levin, J. Grafman, \& H.M. Eisenberg (Eds.), Neurobehavioral Recovery from Head Injury .

Hayden, S., \& Spellacy, F. (I978). The Dichotic Listening Test. Victoria, BC: University of Victoria.

Hillier, S.L. (1997). Awareness and perceptions of outcomes after traumatic brain injury. Brain Injury, $I I, 525-536$.

Hinkeldey, N.S., \& Corrigan, J.D. ( I 990). The structure of head-injured patients' behavioral complaints: A preliminary study. Brain Injury, 4, I I 5I34.

Kazdin, A. (1982). Single-Case Research Designs. New York: Oxford University Press.

Kinsella, G.I., Prior, M., Sawyer, M., Ong, B., Murtagh, D., Eisenmajor, R., Bryan, D., Anderson, V., \& Klug, G. ( I 997). Predictors and indicators of academic outcome in children 2 years following traumatic brain injury. Journal of the International Neuropsychological Society, 3, 608-6 I 6.

Kinsella, G.J. ( I998). Assessment of attention following traumatic brain injury: A review. Neuropsychological Rehabilitation, 8(3), 35 I-375.

Lucyshin, J.M., Albin, R.W., \& Nixon, C.D. (I997). Embedding comprehensive behavioral support in family ecology: An experimental, single-case analysis. Journal of Consulting and Clinical Psychology, 65(2), 24I-25I.

Malec, J.F., \& Thompson, J.M. (I 994). Relationship of the Mayo-Portland Adaptability Inventory to functional outcome and cognitive performance measures. Journal of Head Trauma Rehabilitation, 9(4), I-I 5 .

(Mateer, C.M., \& Mapou, R.L. (I996). (Understanding, evaluating and managing attention disorders after traumatic brain injury. Journal of Head Trauma Rehabilitation, II(2), I-I6.

Mateer, C.M., \& Sohlberg, M.M. (I988). A paradigm shift in memory rehabilitation. In $\mathrm{H}$. Whitaker (Ed.), Neuropsychological Studies of Nonfocal Brain Injury: Dementia and Closed Head Injury (pp. 202-225). New York: Springer-Verlag.

Mateer, C.M., Sohlberg, M.M., \& Crinean, J. (1987). Perception of memory impairment in closed head injury. Journal of Head Trauma Rehabilitation, 2, 74-84. 
Mateer, C.M., Sohlberg, M.M., \& Youngman, P. (I990). The management of acquired attention and memory disorders following mild closed head injury. In R. Wood (Ed.), Cognitive Rehabilitation in Perspective . London: Taylor \& Francis.

Mega, M.S., Thompson, P.M., Cummings, J.L., Back, C.L., Xu, M.L., Zohoori, S., Goldkorn, A., Moussai, J., Fairbanks, L., \& Small, G.W. (I 998). Sulcal variability in the Alzheimer's brain: Correlations with cognition. Neurology, 5O( I), I45-I 5 I.

Neimann, H., Ruff, R.M., \& Baser, C.A. (I990). Computer-assisted attention training in head injured individuals: A controlled efficacy study of an outpatient program. Journal of Clinical and Consulting Psychology, 58, 8 I I-8 I 7.

(Nissen, M.J. (I 986). (Neuropsychology of attention and memory. Journal of Head Trauma Rehabilitation, I(3), I3-2 I.

Obrzut, J.E., Hynd, G.W., \& Obrzut, A. (I983). Neuropsychological assessment of learning disabilities: A discriminant analysis. Journal of Experimental Child Psychology, 35( I), 46-55.

O’Neill, R.E., Horner, R.H., Albin, R.W., Storey, K., \& Sprague, J.R. (1990). Functional Analysis of Problem Behavior: A Practical Assessment Guide. Pacific Grove, CA: Brooks/Cole.

Osgood, G. (I990). The electrophysiological graphical imaging system: Part I. Technical Report No. 90-9, Institute of Cognitive and Decision Sciences, University of Oregon.

Pavese, A., Heidrich, A., Sohlberg, M.M., McLaughlin, K.A., \& Posner, M.I. ( I 999). Pathologies of attentional networks following traumatic brain injury. Manuscript submitted for publication.

Perret, E. (I974). The left frontal lobe of man and the suppression of habitual responses in verbal categorical behaviour. Neuropsychologia, I2(3), 323330.

Ponsford, J.L.\& Kinsella, G.J. ( I 988). Evaluation of a remedial programme for attentional deficits following closed head injury. Journal of Clinical and Experimental Neuropsychology. IO, 693-708.

Ponsford, J. L., \& Kinsella, G. (I992). Attention deficits following closed head injury. Journal of Clinical and Experimental Neuropsychology, I4, 822838 .

Posner, M.I. (I980). Orienting of attention. Quarterly Journal of Experimental Psychology, 4IA, I9-45.

Posner, M., \& Petersen, S.E. (I990). The attention system of the human brain. Annual Review of Neuroscience, $13,25-42$.

Posner, M.I., \& Raichle, M.E. (I994). Images of Mind. New York: Scientific American Books.

Raskin, S.A., \& Sohlberg, M.M. (I996). Prospective memory training. Journal of Head Trauma Rehabilitation, II, 32-5I.

Reitan, R.M., \& Wolfson, D. (I985). The HalsteadReitan Neuropsychological Test Battery: Theory and Clinical Interpretation. Tucson, AZ: Neuropsychology Press.

Richardson, E.D., Springer, J.A., Varney, N.R., Struchen, M.A., \& et al. (I 994). Dichotic listening in the clinic: New neuropsychological applications. Clinical Neuropsychologist, 8(4), 4 I 6-428.

Rosvold, H.E., Mirsky, A.F., Sarason, I., Bransome, E.D., \& Beck, L.H. (I956). A continuous performance test of brain damage. Journal of Consulting Psychology, 20, 343-350.

Ruff, R.M., Light, R.H., Parker, S.B., \& Levin, H.S. ( I 997). The psychological construct of word fluency. Brain \& Language, 57(3), 394-405.

Ruff, R.M., Baser, C.A., Johnson, J.W. et al. (I989). Neuropsychological rehabilitation: An experimental study with head injured patients. Journal of Head Trauma Rehabilitation, 4(3), 20-36.

Russell, E.W., \& D'Hollosy, M.E. (I992). Memory and attention. Journal of Clinical Psychology, 48(4), 530-538.

Sbordone, R.J., Seyranian, R.M., \& Ruff, R.M. ( I998). Are the subjective complaints of traumatically brain injured patients reliable. Brain Injury, I 2 (6), 505-5 I 6.

Sherman, E.M.S., Strauss, E., \& Spellacy, F. (I997). Validity of the Paced Auditory Serial Addition Test (PASAT) in adults referred for neuropsychological assessment after head injury. Clinical Neuropsychologist, II ( I), 34-45.

Simmons-Mackie, N.N., \& Damico, J.S. (I996). Accounting for handicaps in aphasia. Disability and Rehabilitation, I8( I I), 540-549.

Sivak, M., Hill, C.S., \& Olson, P. (I984). Computerized video tasks as training techniques for driving related perceptual deficits in persons with brain damage: A pilot evaluation. International Journal of Rehabilitation Research, 7(389-398).

Sohlberg, M.M., Johnson, L., Paule, L., Raskin, S.A., $\&$ Mateer, C.A. (1994). Attention Process Training II: A Program to Address Attentional Deficits for Persons with Mild Cognitive Dysfunction [rehabilitation materials]. Puyallup, WA: Association for Neuropsychological Research \& Development.

Sohlberg, M.M., \& Mateer, C.A. (1987). Effectiveness of an attention training program. Journal of Clinical and Experimental Neuropsychology, I9, I I 7-I30.

Sohlberg, M.M., \& Mateer, C.A. (I989). Cognitive Rehabilitation: Introduction to Theory and Practice. New York: Guilford Press.

Stablum, F., Leonardi, G., Mazzoldi, M., Umilta, C., $\&$ Morra, S. ( I 994). Attention and control deficits following closed head injury. Cortex, 30, 603-6I 8 .

Stablum, F., Mogentale, C., \& Umiltà, C. (I996). Executive functioning following mild closed head injury. Cortex, 32, 26I-278.

Sternberg, S. (1966). High-speed scanning in human memory. Science, I53, 652-654. 
Stroop, J.R. (I 935). Studies of interference in serial verbal reactions. Journal of Experimental Psychology, I8, 643-662.

Sturm, W., Hartje, W., Orgass, B., \& Willames, K. ( I993). Computer-assisted rehabilitation of attention impairments. In F. Stachowiak (Ed.), Developments in the Assessment of Rehabilitation of Braindamaged Patients .Tubingen, Germany: Narr.

Sturm, W., Willmes, K., Orgass, B., \& Hartje, W. ( I997). Do specific attention deficits need specific training? Neuropsychological Rehabilitation, 7 , 8 I-IO3.

Stuss, D.T., Stethem, L.L., Hugenholtz, H., Picton, T., Pivik, J., \& Richard, M.T. (I989). Reaction time after head injury: Fatigue, divided and focused attention, and consistency of performance. Journal of Neurology, Neurosurgery, and Psychiatry, 52, 742-748.
Van Zomeren, A.H., Brouwer, W.H., \& Deelman, B.G. (I984). Attentional deficits: The riddle of selectivity, speed and alertness. In N. Brooks (Ed.), Closed Head Injury: Psychological, Social, and Family Consequences . Oxford: Oxford Press.

Whyte, J., Hart, T., Schuster, K., Fleming, M., Polansky, M., \& Coslett, H.B. (I997). Effects of methylphenidate on attentional function after traumatic brain injury: A randomized, placebo-controlled trial. American Journal of Physical Medicine and Rehabilitation, 76, 440-50.

Wilson, B.A., Alderman, N., Burgess, P., Emslie, H., \& Evans, J. ( I 996). Behavioural Assessment of the Dysexecutive Syndrome. Bury St. Edmunds, Suffolk: Thames Valley Test Company.

Wood, R.L., \& Fussey, I. (I987). Computer assisted cognitive retraining: A controlled study. International Disability Studies, 9, I49-I 53. 


\section{APPENDIX}

\section{Examples of changes perceived to be related to treatment given during structured interviews}

Comments following attention process training from participant interviews:

- I can remember phone numbers better (4 individuals).

- I can watch a whole movie.

- I read more (2 individuals).

- School is a lot easier because I can read better and pay attention more.

- I check my memory log more often.

- When I type up the poems I have written, I don't have to look back at the page for each word.

- I remember my appointments better.

- I am less rigid and ritualized about everything and I don't have to do stuff in the same way, like when I clean the barn I can insert different steps and don't double check everything.

Comments following attention process training from significant other interviews:

- She can hold on to a conversation better.

- She remembers more of her appointments on her own.

- Her reading is better.

- He is reading more.

Comments following placebo intervention from participant interviews:

- I check my day-timer and e-mail more often.

- I check my calendar.

- I know more where I am going when I leave my place.

- I remember my appointments.

- I remember to put appointments in my book.

- Getting up in the morning feels easier.

Comments following placebo intervention from significant other interviews:

- He remembers where he was sitting. 